\title{
ZS Research Square

\section{Assessment of risk factors for early childhood caries at different ages and caries levels in Shandong, China and guidance for dental health education: a cross-sectional study}

meng zhang

Shandong University

Xinyue Zhang

Shandong University

Yuan Zhang

Shandong University

Yanan Li

Shandong University

Chunchun Shao

Shandong University

Shijiang Xiong

Shandong University

Jing Lan

Shandong University

Zhifeng Wang ( $\nabla$ kqwzf@sdu.edu.cn )

Research article

Keywords: Early childhood caries, Dental health education, Risk factor, Oral health care, brushing, eating sugary, feeding.

Posted Date: September 5th, 2019

DOI: https://doi.org/10.21203/rs.2.13981/v1

License: (1) This work is licensed under a Creative Commons Attribution 4.0 International License. Read Full License 


\section{Abstract}

Background Dental health education (DHE) plays a vital role in the prevention of early childhood caries (ECC). There are a large number of studies on ECC risk factor assessment to enrich the content of DHE, but such research rarely provides some guidance and assistance for the design and optimization of DHE strategies. Therefore, this study aims to improve this information by analyzing risk factors at different ages and caries levels.Methods The children aged 3-5-year-old was enrolled in this cross-sectional study. Their oral condition was evaluated according to WHO criteria. Simultaneously, a questionnaire containing the oral health knowledge, attitude, practice (KAP) was completed by guardians. Chi-square test and regression analysis were performed to analyze the ECC difference of KAP variables in different grouping methods, and to construct models to assess the risk factors. Results A total of 1301 children's data were included for statistical analysis. Caries prevalence was $64.6 \%$, the dmft mean was 3.15. Independent associations with increased risk for ECC were age, some KAP variables related to feeding, sugar consumption, and brushing ( $P=0.000$ based on multivariable regression analysis). 3-year-old group were primarily associated with some KA variables $(P=0.000)$. As children grow up, practice variables became the main risk factor (4- and 5-year old age group model: $P=0.014$ and 0.000 ). And more practice variables were independently associated with the severe-caries-group than mild-caries-group $(P=0.000)$.Conclusion This survey demonstrates that the ECC-related risk factors in different ages and different caries levels are different, which will facilitate us to design more personalized and strategic DHE content.

\section{Background}

Early childhood caries (ECC) mainly refer to the presence of decayed, missing due to caries and filled teeth (dmft) in the oral of children under 71 months[1, 2]. According to the Lancet journal statistics, the incidence of deciduous teeth ranks fifth in the world.[3] And it shows a significant negative impact on children's chewing, growth and development $[4,5]$. So strengthening the prevention of ECC has always been the most urgent and significant task for dentists and even the whole society. The current prevention of caries is mainly achieved through the following two aspects: i) Professional preventive measures implemented in the hospital: including fluoride coating, pit and fissure sealing, and forth.[6-8]; ii) Self-oral health care (S-OHC) behavior: in addition to brushing, gargle, using gloss to remove the dental plaque, there are also the control of the high-risk factors related to caries such as sugar consumption, feeding habits,etc. $[7,9,10]$. Access to these information is primarily through the dental health education (DHE, covering hospital, school, community andnetwork platforms)[11].

DHE has always been a vital part of the caries prevention[1], which brings intuitive guidance and assistance to people. For children, considering the imperfections in their cognitive level and self-behavior ability, their behavior, habits, consciousness are influenced by the knowledge level, ideology and behavioral habit of the guardian[12,13]. Therefore, guardiansare invited to enter the child's health education system, acting as a good model, guidance and supervision medium,aimed toachieve the purpose of prevention more cost-effectively[14]. However, although there are large number of studies on ECC risk factor assessment currently, which provides a sufficient reference for the establishment of DHE 
content, there is almost no research to analyze the risk factors in the different stages of deciduous dentition and different caries levels, which hinders us to design DHE content more specifically and strategically, andthenprevent dental caries more effectively.

Therefore, this cross-sectional study intends to base on the analysis of the correlation between the guardian knowledge, attitude and practice (KAP. Practice refers to the $\mathrm{OHC}$ behavior of the guardian on the child) and ECC in Shandong, China, obtains the caries-related risk factors, and explores the risk factors at different agesand different caries levels. Summarize these results, further discuss the key content of children's DHE and how to configure DHE details for children of different ages and different caries levels to provide guidance and evidence support for optimizing DHE strategies.

\section{Methods}

This cross-sectional study was conducted in 2015-2016 in Shandong province, which was part of the $4^{\text {th }}$ National Oral Health Survey in China, and had been approved by the Ethics Committee of the Chinese Stomatological Association (NO.2014-003).

\section{Sample selection}

3-5 year old children lived in Shandong province were our target population. The sample size was determined by the equal allocation of the national plan, 36 children from each age group in each kindergarten were surveyed, so at least 1296 sample data should finally be included in the study. Incorporate sample population according to the following multi-stage stratified sampling method:

1. The probability proportionate to size sampling (PPS) method determined the two districts and two counties for survey.

2. 3 kindergartens were randomly selected from each region

3. Using cluster sampling, 36 children were selected from each age group in each kindergarten.

\section{Examiners selection and training}

Three examiners from the Hospital of Stomatology were selected and trained. In order to ensure the consistency of clinical practiceinter- and intra- examiners, each examiner randomly enrolled three participants to examinations. Before calculate the Kappa value, every examination results must be calibrated with a qualified examiner. The mean Kappa value of intra-examiners was determined through re-examine the samples, the mean Kappa value of inter-examiners was calculated through mutual examine samples. The clinical practice training would be ended until the Kappa value is greater than 0.8 .

\section{Informed consent and questionnaire}

After informed all kindergartens enrolled in this research the survey procedure and got support, our team would ask guardians to write informed consent. When the oral examination for children was performing, 
a questionnaire would be simultaneously completed by the guardians. The questionnaire contents mainly include:

i) Personal and family information.

ii) $\mathrm{OHC}$ knowledge, mainly involved in the effect of brushing, bacteria, sugar, pit and fissure sealing, fluoride and other factors on the teeth and gums.

iii) $\mathrm{OHC}$ attitude, mainly to investigate whether the guardian believes that oral health is extremely important.

iv) Guardians-guided $\mathrm{OHC}$ practice for children, mainly get information about feeding, eating sugar, brushing, and other habits.

\section{Caries assessment}

A ball-end community periodontal index probe was used to assess dental status according to the WHO guidelines[16]. In addition, the written version of the examination results and treatment recommendations would be send to guardians to increase the significance of the survey.

\section{Statistical analysis}

The IBM SPSS Statistics version 17.0 was used to perform the statistical analyses. To examine the difference factors between different groups, Chi-square test or Fisher's test was used for categorical variables, and $z$ test for post hoc comparisons. Ordinal logistic regression analysis and Binary logistic regression analysis were used to perform the multivariable regression analysis. Differences were considered to be significant at $P<0.05$.

In addition, $\mathrm{dmft}$ was divided into three groups ( $\mathrm{dmft}=0$; $\mathrm{dmft}=1 \sim 3$; $\mathrm{dmft}=4 \sim 20)$ to facilitatestatistical analysis. And considering the data for Q7-11 will be available only when the answer to Q6is 'yes'. Therefore, in multivariable regression analysis based on various grouping ways, the following two submodels would be separately constructed, sub-model I with all children ( $n=1301$, do not cover Q7-11) and sub-model II only with those children having brushing habits $(n=691$, covering Q7-11). Furthermore, regression models for each age group and each dmft level were also analyzed. In order to facilitate ordinal regression analysis, we adjusted for education, income, Q21a-f_group, Q21_sum_group, Q22_sum_group (grouping based on the sum of question options), Q3_group, Q4a_group, Q11_group variables.

\section{Results}

A total of 3 cities including 2 districts and 2 counties in Shandong were sampled. 1330 preschool children were intended to be invited. However, 18 children's guardians decline to sign the informed consent, 6 
questionnaires cover missing information, 5 children transfer to school, so the remaining 1301 children's data were included in the final statistical analysis.

The caries rate (CR) of 3-5-year-old children was $64.6 \%$, and mean dmft was 3.15, the proportion of $\mathrm{dmft}=2$ was as high as $13.2 \%$. The rates of 3,4 , and 5 age group were respectively $51.1 \%, 67.8 \%, 73.9 \%$, the mean dmft were $2.16,3.21,4.01$ (see Table 1). $96.4 \%$ of decayed teeth were waiting to be treated.

\section{Difference analysis}

The characteristics and difference analysis results of the survey (including demographics andKAP variables) are shown in Table 1-3 and Additional Table S1.

The demographic characteristic shows in Table 1, ECC rates increasedwith age $(51.1 \%$ vs $67.8 \%$ vs $73.9 \%$, $P=0.000$ ), whereas no statistical differences were shown in different genders, regions, education background and income.

The distribution characteristic of KAP variables shows in Additional Table S1. 80.9\% of the questionnaires were completed by parents and the rest were done by older people, and the CR between them showed no significant difference (data not shown). Analysis from perspective of $\mathrm{OHC}$ knowledge (Q22a-h), 66.0\%-84.4\% of people could correctly answer Q22b-22f, yet only 30.7\% known that gum bleeding is not a normal phenomenon when brushing teeth (Q22a), and 16.0\% and $27.7 \%$ known that fit and fissure sealing or fluoride can protect teeth (Q22g, h). The analysis found thatthe CR of Q22d, e, $\mathrm{g}$ variable show significant difference $(P=0.026,0.013,0.030$ respectively), which mainly involve in bacteria and sugar can induce the caries, as well as the pit and fissure sealing can protect teeth. However, after the $\mathrm{dmft}$ number was subdivided into two groups, $0<\mathrm{dmft} \leq 3$ group (Mild, MCG) and $\mathrm{dmft} \geq 4$ group (Severe, SCG), only Q22g showed statistical difference $(P=0.033)$. Curiously, among these difference variables, the $\mathrm{CR}$ of those who answered incorrectly were lower than those who answered correctly.

Analysis from perspective of OHC attitude (Q21a-f), 81.6\%-98.8\% of people answer Q21a-e correctly, but only $35.8 \%$ believe that the mother's oral health affects the child's oral health (21f). The children raised by those guardians who believe that whether the teeth are health is not related to their own protection unexpectedly have a slightly lower CR than those who do not think so (Q21c, $56.7 \%$ vs $66.4 \%, P=0.005$ ). In addition, after respectively summing up the answers to the Q21 and Q22 (named "Q21/Q22_sum_group"), statistics showed that group 1 with high correct rates in Q21_sum_grouphad higher $\mathrm{CR}(67.0 \%$ vs $61.8 \%, P=0.049)$.

Analysis from perspective of $\mathrm{OHC}$ practices (Q3-11). When infants younger 6 months were fed in different ways, their oral condition would be different (Q3). The CR of the totally artificial feeding subgroup (45\%) was significantly lower than other feeding methods $(P=0.005)$. In addition, the different frequency and time of eating sweets, the child's caries condition was significantly different (Q4-5). But the difference was only shown in the Q5 about the frequency of eating sugary before going to bed at night, which showed a positive correlation trend with the caries ( $73.8 \%$ vs $66.8 \%$ vs $58.6 \% ; P=0.002$ ). In Q10, the rates 
in children brushing with toothpaste were much higher than those children who do it without toothpaste (65.2\% vs $25.0 \%, P=0.018)$. Similarly, children who brush their teeth with fluoride toothpaste also had higher rates $(80.0 \%$ vs $68.1 \%$ vs $62.2 \%, P=0.016)$. Children who have frequent toothache or discomfort in the past 12 months (Q12) or who have seen a doctor to the hospital (Q13) usually have a higher caries rate $(88.1 \%-100.0 \%, 81.0 \%, P=0.000)$. And the analysis results of $Q 6-9$ showed no statistical difference.

Considering the age was a significant difference variable, we would separately analyze the differences in the distribution of covariates in each age group to eliminate the potential effects of age. Those variables with differences are shown in Table 2. In the 3-year-old group, there was 1 attitude variable (Q21f) and 5 practice variables (Q3_group, Q5, Q11-13) with statistical differences.In the 4-year-old group, gender and4 practice variables $(\mathrm{Q} 5, \mathrm{Q} 8, \mathrm{Q12}-13)$ have statistical differences.Among them, those children who didn't brushing daily in Q8 showed the lowest CR in the SCG $(18.4 \%, P=0.025)$. According to further statistics, $66.6 \%(n=6)$ of these children lived in Linyi district, a place where tough pancakes are the staple food. In the 5-year-old group, 1 knowledge variable (Q22d), 1 attitude variable (Q21c) and 5 practice variables (Q4a, 5, 11-13) have statistical differences.The difference trend of these variables are similar to the results of the overall analysis $(P<0.05)$.

Based on the above results, we also found that the difference variables were different in the MCG and SCG. Therefore, a new difference analysis grouped by the degree of caries was implemented (Table 3 ). In the MCG, there are only 4 difference variables (Q22e, 21c, 3, 12). In the SCG, However, as much as 13 variables have significant difference, including age, Q22d, 22e, 22g, 21b, 21c, 21_sum_group, and Q3, 5, 7, 10-13 $(P<0.05)$. All of these variables also showed similar trends to the overall analysis results $(P<0.05)$.

\section{Regression analysis}

The results of logistic regression analyzes based on the overall, age and the carieslevel (model 1-3) were shown in Table 4-6. Each model contains two sub-models (I and II).

In the overall analysis model (model 1, Table 4), age, Q22e, $\mathrm{g}$ and Q5 variables were the caries risk factors for all children $(P=0.000)$, while age, Q21_sum_group and Q11 variables were the risk factors for those children with brushing habits $(P=0.000)$. In the analysis model of the 3-5-year-old group (model 2 , Table 5), model 2-1 of 3-year-old group reveals that Q21f, 21_sum_group, 22e and Q13 were the risk factors for all kids $(P=0.000)$. If we added the Q7-11 variables, the Q22 in the model would lose meaning, so only Q21f, 21_sum_group and Q11 were the risk factors in sub-model II $(P=0.000)$. In the model 2-2 of 4-yearold group, only Q5 and Q8, 13 respectively made these two sub-models meaningful ( $P=0.014$ and 0.001$)$. The model 2-3 of 5-year-old group showed that Q21c, Q4a, 5, 13 and Q5,11, 13 were risk factors for these two sub-models, respectively $(P=0.000)$. Furthermore, model 3 (Table 6$)$, which grouped based on the caries level, told us that in model 3-1 with mild caries, only age, Q21c and Q3, 12 were risk factors $(P=0.000)$. Once the Q7-11 variables were added, the model or variable itself lost statistical significance. While in thesevere caries model 3-2, age, Q22e and Q5, 12-13 were caries risk factors for all children $(P=0.000)$, and age, Q21b, Q5 and Q11-13 were risk factors for children with brushing habits $(P=0.000)$. 


\section{Discussion}

The present study investigated the city in which the author lived, Shandong province, it's the third largest economic city with GDP in China, has a population of nearly 100 million people. Among them, Linyi city is the city with the largest population and area. And this city has a very special diet, most residents take a hard and tough pancake as their staple food. The other two cities obtained by multi-stage stratified sampling-Weifang and Weihai take the steamed bread as the main food. This combination of multi-stage stratified sampling and cluster sampling not only allows us to obtain samples that represent the oral health status of the province, but also covers areas with different dietary habits. Out of a total of 1330children aged 3-5-year-old, 1301 familiesprovide complete and reliable data information, the response rate is as high as $97.8 \%$, this is very satisfying.

The CR of 3-5-year-old children in Shandong province is $64.6 \%$, slightly higher than the national data $(62.5 \%)$, while the $\mathrm{dmft}$ mean and the untreated rate of dental cariesare lower than the national data (3.15 vs $3.35 ; 96.4 \%$ vs $96.9 \%$ )[17]. These data give us an opportunity to analyze the risk factors associated with ECC in Shandong province, and provide targeted theoretical support for the DHE content.

Consistent with most ECC risk assessment studies, age has always beenan obvious influencing factor[18], this is also in line with the etiology of dental caries[15]. However, there is little research to access the risk factors for each agebut to evaluate 3-5-year-old children as a whole[19, 20]. So we speculated that although the age span is small, different ages may have different risk factors. As we thought, both the Chi-square test andthe corresponding regression model confirm this (Table 2-6). The risk factors for 3-year-old group were mainly KA variables (Q21f, 21_sum_group, 22e, Q13), while the 5year-old group involved practice variables $(Q 4 a, 5,13)$. Practice variables are also mainly associated with serious caries condition (Table 6). In addition, when analyzing sub-models I and II, we found that for all children, knowledge variables and eating sugar habits are high-risk factors, but for children who have already developed brushing habits, attitude variables and brushing habits will become the main risk factors. These results provide a great enlightenment for clinical and oral health education: different advice and education content should be paid on different conditions, this responds to the precision medicine.

Therefore, based on the above analysis, we speculate that Children's DHE should have a system to carry out a series of education guidance, in the early stage of deciduous dentition (3-year-old), the focus should be on enriching the oral health knowledge of guardians, cultivating children's tooth care awareness and habits including the control of some high-risk factors. Considering that children's self-behavioral ability is weak, there is no need to overemphasize whether oral health behavior is criterion. This part is mainly supervised and completed by parents. While with the increase of age, improvement of self-behaviour ability and the development of health habits, whether to master the correct and standardized oral hygiene methods will be transformed into key training content, such as how to properly brush teeth. This part is a key step to bridge the gap between knowledge and practice, which is primarily done by the children themselves. 
Furthermore, although the present study obtained some knowledge- and attitude-related risk variables, part of which are negatively correlated with $\mathrm{dmft}$. Some RCTs researches confirmed that the children of guardians who received oral health education usually have lower level of ECC[21, 22], yet some showed no significant effect[23]. This study gave a negative correlation. After precluding the possibility that data entry and statistical methods may be problematic, we speculate that this may be because there is still a gap between the acquisition of KA variables related to $\mathrm{OHC}$ and the actual action. After all, the earning of knowledge only gives us an opportunity to improve behavior, but the final behavior is affected by many factors[24]. At the same time, it also reflects that our work in promoting oral health behavior is not enough. Education is only the first step, a lot of work is still needed to bridge the gap.

Brushing has always been considered the primary and most effective way to prevent dental caries. Many studies have confirmed that the frequency and time of brushing affect the occurrence of ECC[25, 26], but more studies have found that they are not relevant[27-29], which is consistent with the results of the present study. This may be because the child's $\mathrm{OHC}$ ability is weak, or because the caries lesion of children is more likely to occur in the interproximal[30], while the prevention of interproximal lesions by brushing is restricted, which requires the assistance of interdental cleaning devices to achieve better completion[31]. Regrettably, the role of dental floss in preventing ECC is blank in present study, and research in this area is also limited. Therefore, increasing the information of using dental floss in future research may bring us more outcomes and admonition.

The frequency of eating sweets before going to bed and whether or not to use fluoride toothpaste is the most relevant behavioral risk factors obtained in this study. The positive correlation between the frequency of eating sugar and the caries has been largely confirmed, especially for those sweets before sleeping[25, 32, 33], The children who had sweet snacked twice or more daily had significant higher CR compared to those who snacked less than twice daily[34]. In addition, the function of fluoride in protecting teeth and preventing caries has also been widely confirmed[35-37]. Unfortunately, in present study, only $27.7 \%$ of caregivers knew that fluoride could protect teeth. While in order to prevent fluorosis, children under the age of 6 are not recommended to use fluoride toothpaste on their own, but to protect teeth primarily by iatrogenic fluoride[38]. Therefore, the barren of fluoride knowledgemaybe prevent parents from scientifically protecting children's teeth.

What's more, the positive correlation between visiting dentists and dmft indicates that the parents bring children to see doctor only when their teeth have problems. This is contrary to the exhortation for regular inspections to prevent oral problems[39], which also reflects the lack of prevention concepts of parents in Shandong, and this is whereDHE needs to be particularly strengthened.

The limitation of this study: the issues in the $\mathrm{OHC}$ knowledge and attitude line designing in this research questionnaire are relatively basic and traditional. Some questions about the impact of proven risk factors on caries andsomemore professionaloral health KAP variables, such as the application of dental floss, are not covered, which has led us to lose the opportunity to assess the impact of these variables on ECC. 
Therefore, more information is waiting to be collected to further analyze the correlation between KAP and ECC.

\section{Conclusion}

The ECC-related risk factors obtained in this study, such as age, sugar consumption, brushing habits, etc., have been confirmed in previous studies,while a more in-depth analysis brings us some other interesting results: the risk factors for different ages and different levels of caries were different. These results provide some enlightenments for clinical and DHE strategy: in the early stage of deciduous dentition, the focus should be on enriching oral health knowledge of guardians and cultivating children's toothcare habits and awareness. With the increase of age and the gradually formation of self-behavior ability of children, the focus will transfer to the training of correct $\mathrm{OHC}$ methods, such as the use of toothbrush and dental floss. Of course, further clinical research is needed to further refine the relevant information and confirm the effectiveness of this strategy.

\section{List Of Abbreviations}

ECC:early childhood caries; KAP:knowledge, attitude and practice; OHC: oral health care; DHE: dental health education; WHO: world health organization; dmft: decayed, missing and filled teeth; CR: caries rate; MCG: mild caries group; SCG: serious caries group; RCT: randomized controlled trial; OR: odd rates; $\mathrm{Cl}$ : confidence interval.

\section{Declarations}

Ethics approval and consent to participate: This study had been approved by the Ethics Committee of the Chinese Stomatological Association (NO.2014-003) and the informed consent was obtained from a legal guardian for participants under 16 years old.

Consent for publication: Not applicable.

Availability of data and materials: The datasets used andanalyzed during the current study are available from the corresponding author on reasonable request.

Competing interests: The authors declare that they have no competing interests.

Funding:All phases of this study were supported by the Chinese Stomatological Association and School \& Hospital of Stomatology, Shandong University. The design of this study and collection, analysis, and interpretation of data and the manuscript writing are funded by the Key Technology Research and Development Program of Shandong (CN), grand number is 2019GSF108278, and 2019GSF108184.

Authors' contributions: ZF W, J Land SJ X conceptualized and designed the study, reviewed and revised the manuscript. M Z collected and organized data, carried out the statistical analyses, drafted and revised 
the manuscript. Y Zinstructed the methods and strategies of statistical analysis, and reviewed and revised the manuscript. XY Z and YN L collected, organized and input data. CC S conducted the statistical analysis of the data. All authors read and approved the final manuscript.

\section{Acknowledgements}

Thank you very much to the Chinese Stomatological Associaiton for the raw data of the survey they provided. Thank you also for the cooperation and help of various kindergartens.

\section{References}

1. Selwitz RH, Ismail Al, Pitts NB: Dental caries. Lancet (London, England) 2007, 369(9555):51-59.

2. Dentistry AAOP, Pediatrics AAO: Policy on early childhood caries (ECC): classifications, consequences, and preventive strategies. Pediatric dentistry 2011, 30(7 Suppl):31-33.

3. Global, regional, and national incidence, prevalence, and years lived with disability for $\mathbf{3 2 8}$ diseases and injuries for 195 countries, 1990-2016: a systematic analysis for the Global Burden of Disease Study 2016. Lancet (London, England) 2017, 390(10100):1211-1259.

4. Casamassimo PS, Thikkurissy S, Edelstein BL, Maiorini E: Beyond the dmft: The Human and Economic Cost of Early Childhood Caries. The Journal of the American Dental Association 2009, 140(6):650-657.

5. Yumiko K, Masayasu K, Toshiyuki S: Early Childhood Caries. Journal of the American Dental Association 2011, 140(10):150-152.

6. Stephen KW: Use of fluoride. Lancet (London, England) 1999.

7. NB P, DT Z, PD M, K E, JA W, F R-G, J T, S T, G T, A I: Dental caries. Nature reviews Disease primers 2017, 3(undefined):17030.

8. White JR, Nagarajan N, Pop M: Statistical methods for detecting differentially abundant features in clinical metagenomic samples. PLoS computational biology 2009, 5(4):e1000352.

9. S T, M S, H T, K S, S T, K K: Secondhand smoke and incidence of dental caries in deciduous teeth among children in Japan: population based retrospective cohort study. BMJ (Clinical research ed) 2015, 351(undefined):h5397.

10. R P, A C, BJ M, WM T, A T, MR S, TE M: Association between children's experience of socioeconomic disadvantage and adult health: a life-course study. Lancet (London, England) 2002, 360(9346):16401645.

11. Petersen PE, Bourgeois D, Ogawa H, Estupinan-Day S, Ndiaye C: The global burden of oral diseases and risks to oral health. Bulletin of the World Health Organization 2005, 83(9):661-669.

12. C F, JK W, JA F, DL H, KW C, CJ M, VA M, WE M, D M, TI K et al: Good-parent beliefs of parents of seriously ill children. JAMA pediatrics 2015, 169(1):39-47.

13. Dhana K, Haines J, Liu G, Zhang C, Wang X, Field AE, Chavarro JE, Sun Q: Association between maternal adherence to healthy lifestyle practices and risk of obesity in offspring: results from two 
prospective cohort studies of mother-child pairs in the United States. BMJ 2018.

14. Selwitz RH, Ismail Al, Pitts NB: Dental caries. The Lancet, 369(9555):51-59.

15. N Z, H Z, Y C, W J, X L, Y T, D C, H C: Dental caries and associated factors in $\mathbf{3}$ to 5-year-old children in Zhejiang Province, China: an epidemiological survey. BMC oral health 2019, 19(1):9.

16. (WHO). WHO: Oral health surveys: basic methods. 5th edition.Geneva: WHO 2013:p.42-47.

17. Du M, Li Z, Jiang H, Wang X, Ping Feng X, Yu Hu D, Lin HC, Wang B, Si Y, Xiao Wang C et al: Dental Caries Status and its Associated Factors among 3- to 5-year-old Children in China: A National Survey, vol. $21 ; 2018$.

18. H I, P A, RJ B, M W: Association between infant breastfeeding and early childhood caries in the United States. Pediatrics 2007, 120(4):e944-952.

19. Bastos JL, Gigante DP, Peres KG, Nedel FB: Social determinants of odontalgia in epidemiological studies: theoretical review and proposed conceptual model. Ciencia \& saude coletiva 2007, 12(6):1611-1621.

20. Kanasi E, Dewhirst FE, Chalmers NI, Kent R, Jr., Moore A, Hughes CV, Pradhan N, Loo CY, Tanner AC: Clonal analysis of the microbiota of severe early childhood caries. Caries research 2010, 44(5):485497.

21. Plutzer K, Spencer AJ: Efficacy of an oral health promotion intervention in the prevention of early childhood caries. Community dentistry and oral epidemiology 2008, 36(4):335-346.

22. SZ M, JI V, M V-G, MM V: A cluster randomised trial of effectiveness of educational intervention in primary health care on early childhood caries. Caries research 2009, 43(2):110-118.

23. Jiang EM, Lo ECM, Chu CH, Wong MCM: Prevention of early childhood caries (ECC) through parental toothbrushing training and fluoride varnish application: A 24-month randomized controlled trial. Journal of Dentistry 2014, 42(12):1543-1550.

24. Casamassimo PS, Thikkurissy S, Edelstein BL, Maiorini E: Beyond the $\mathrm{dmft}$ : the human and economic cost of early childhood caries. Journal of the American Dental Association (1939) 2009, 140(6):650-657.

25. XL G, CY H, YC X, T L, D K, HB H: Behavioral pathways explaining oral health disparity in children. Journal of dental research 2010, 89(9):985-990.

26. J A, Y A, M O, K N, M M: Contributions of social context to inequality in dental caries: a multilevel analysis of Japanese 3-year-old children. Community dentistry and oral epidemiology 2008, 36(2):149-156.

27. Begzati A, Berisha M, Meqa K: Early childhood caries in preschool children of Kosovo - a serious public health problem. Bmc Public Health 2010, 10(1):788.

28. van Palenstein Helderman WH, Soe W, van 't Hof MA: Risk Factors of Early Childhood Caries in a Southeast Asian Population, vol. 85; 2006.

29. Zhou Y, ., Lin HC, Lo ECM, Wong MCM: Risk indicators for early childhood caries in 2-year-old children in southern China. Australian Dental Journal 2015, 56(1):33-39. 
30. V P, C K, J A, A C, R H, F G-G, J K, R H-W: Longitudinal study of caries progression in 2- and 3-year-old German children. Community dentistry and oral epidemiology 2016, 44(4):354-363.

31. HV W, L M, T PP, D S, TM J, P I, JE C: Home use of interdental cleaning devices, in addition to toothbrushing, for preventing and controlling periodontal diseases and dental caries. The Cochrane database of systematic reviews 2019, 4(undefined):CD012018.

32. $\mathrm{T} \mathrm{H}, \mathrm{E} \mathrm{N}, \mathrm{M} \mathrm{O}, \mathrm{K} \mathrm{T}, \mathrm{H}$ A: Dental caries in 3-year-old children and smoking status of parents. Paediatric and perinatal epidemiology 2008, 22(6):546-550.

33. M F, R J, G E, N S, J C, AF Z, M A, GK S, S D, DT Z: Identification of caries risk factors in toddlers. Journal of dental research 2011, 90(2):209-214.

34. KJ C, SS G, D D, SKY L, ECM L, CH C: Dental caries status and its associated factors among 5-yearold Hong Kong children: a cross-sectional study. BMC oral health 2017, 17(1):121.

35. Twetman S, Axelsson S, Dahlgren $H$, Holm AK, KãđLlestã¥L C, LagerlãqF F, LingstrãqM P, Mejã rl, Nordenram G, Norlund A: Caries-preventive effect of fluoride toothpaste: a systematic review. Acta Odontologica Scandinavica 2003, 61(6):347-355.

36. Walsh T, Worthington H, Glenny A-M, Appelbe P, Cc Marinho V, Shi X: Fluoride toothpastes of different concentration for preventing dental caries in children and adolescents, vol. 20; 2010.

37. Kokoceva-Ivanovska OR, Sarakinova O, Zabokova-Bilbilova E, Mijoska AN, Stavreva N: Oral Hygiene Index in Early Childhood Caries, Before and After Topical Fluoride Treatment. Open Access Macedonian Journal of Medical Sciences 2018, 6(2):378-383.

38. R C, A C, B Z, JP M, M P: Preventing dental caries in children <5 years: systematic review updating USPSTF recommendation. Pediatrics 2013, 132(2):332-350.

39. Oral health: prevention is key. Lancet (London, England) 2009, 373(9657):1.

\section{Tables}

Table 1. General demographic characteristics of participants and the distribution of dmft. $(n,(\%))$ 


\begin{tabular}{|c|c|c|c|c|c|c|}
\hline Variables & $\mathrm{dmft}=0$ & $1 \leq \mathrm{dmft} \leq 3$ & $\mathrm{dmft} \geq 4$ & $P$ & dmft $>0$ & $P$ \\
\hline Gender & & & & \multirow{3}{*}{0.270} & & \multirow{3}{*}{0.616} \\
\hline male & 235(36.1) & 184(28.3) & $232(35.6)$ & & $416(63.9)$ & \\
\hline female & $226(34.8)$ & $210(32.3)$ & $214(32.9)$ & & $424(65.2)$ & \\
\hline \multicolumn{4}{|l|}{ Age } & \multirow{4}{*}{0.000} & & \multirow{4}{*}{0.000} \\
\hline 3 & $203(48.9)^{\mathrm{a}}$ & $113(27.2)^{\mathrm{a}}$ & $99(23.9)^{\mathrm{a}}$ & & $212(51.1)^{*}$ & \\
\hline 4 & $142(32.2)^{b}$ & $153(34.7)^{\mathrm{a}}$ & $146(33.1)^{b}$ & & $299(67.8)^{* *}$ & \\
\hline 5 & $116(26.1)^{b}$ & $128(28.8)^{\mathrm{a}}$ & $201(45.2)^{\mathrm{C}}$ & & $329(73.9)^{* * *}$ & \\
\hline \multicolumn{4}{|l|}{ Region } & \multirow{7}{*}{0.245} & & \multirow{7}{*}{0.343} \\
\hline urban & 227(34.9) & 202(31.0) & 222(34.1) & & $424(65.1)$ & \\
\hline weihai & $111(34.3)$ & $94(29.0)$ & $119(36.7)$ & & $213(65.7)$ & \\
\hline hedong, linyi & 116(35.5) & 108(33.0) & 103(31.5) & & $211(64.5)$ & \\
\hline rural & $234(36.0)$ & 192(29.5) & $224(34.5)$ & & $416(64.0)$ & \\
\hline weifang & 106(32.7) & 93(28.7) & 125(38.6) & & 218(67.3) & \\
\hline pingyi, linyi & 128(39.3) & $99(30.4)$ & $99(30.4)$ & & 198(60.7) & \\
\hline \multicolumn{6}{|l|}{ Education } & \multirow{4}{*}{0.699} \\
\hline $\begin{array}{c}\text { Elementary } \\
\text { school and } \\
\text { below }\end{array}$ & 88(34.9) & 75(29.8) & $89(35.3)$ & \multirow[t]{3}{*}{0.807} & 164(19.5) & \\
\hline $\begin{array}{l}\text { junior high } \\
\text { school }\end{array}$ & 192(36.8) & 150(28.7) & $180(34.5)$ & & $330(39.3)$ & \\
\hline $\begin{array}{l}\text { Senior high } \\
\text { school and } \\
\text { above }\end{array}$ & $181(34.3)$ & $169(32.1)$ & 177(33.6) & & $346(41.2)$ & \\
\hline \multicolumn{6}{|l|}{ Income } & \multirow{4}{*}{0.357} \\
\hline less than & $111(34.0)$ & $100(30.7)$ & 115(35.3) & \multirow[t]{3}{*}{0.133} & $215(27.4)$ & \\
\hline $40,000-60,000$ & 166(38.0) & $111(25.4)$ & $160(36.6)$ & & 271(34.5) & \\
\hline $\begin{array}{c}\text { more than } \\
70,000\end{array}$ & 153(33.8) & 151(33.3) & 149(32.9) & & $300(38.2)$ & \\
\hline
\end{tabular}

a , b c. Differences in caries rate between row variables in subgroups with different levels of caries, the same mark represents no difference between the two variables.

${ }^{*},{ }^{* *},{ }^{* \star}:$ The difference in caries rates between row variables, the same mark represents no difference between the two variables.

Table 2. Differential KAP variables in different age groups. (n, (\%)) 


\section{For 3-year-old group ( $\mathrm{n}=415)$}

\section{Attitude}

Q21f_group Does the mother's unhealthy teeth affect the child's teeth?

$\begin{array}{ccccc}\text { correct answer } & 82(54.7)^{\mathrm{a}} & 43(28.7)^{\mathrm{a}} & 25(16.7)^{\mathrm{a}} & 0.032 \\ \text { wrong answer } & 121(45.7)^{\mathrm{a}} & 70(26.4)^{\mathrm{a}} & 74(27.9)^{\mathrm{b}} & \end{array}$

\section{Practice}

Q3_group Feeding method within 6 months of birth

$\begin{array}{ccccc}\text { complete or mainly breastfeeding } & 156(46.8)^{\mathrm{a}} & 97(29.1)^{\mathrm{a}} & 80(24.0)^{\mathrm{a}} & 0.016 \\ \text { complete or mainly artificial feeding } & 32(71.1)^{\mathrm{b}} & 7(15.6)^{\mathrm{a}} & 6(13.3)^{\mathrm{a}} & \\ \text { half breastfeeding and half artificial } & 15(40.5)^{\mathrm{a}} & 9(24.3)^{\mathrm{a}} & 13(35.1)^{\mathrm{a}} & \end{array}$

Q5 Frequency of eating sweet before going to bed at night

\begin{tabular}{|c|c|c|c|}
\hline often & $13(36.1)^{a}$ & $15(41.7)^{\mathrm{a}}$ & $8(22.2)^{a, b}$ \\
\hline occasionally & $118(47.0)^{\mathrm{a}}$ & $63(25.1)^{\mathrm{a}}$ & $70(27.9)^{b}$ \\
\hline never & $72(56.3)^{a}$ & $35(27.3)^{a}$ & $21(16.4)^{\mathrm{a}}$ \\
\hline
\end{tabular}

Q11 Whether to use fluoride toothpaste

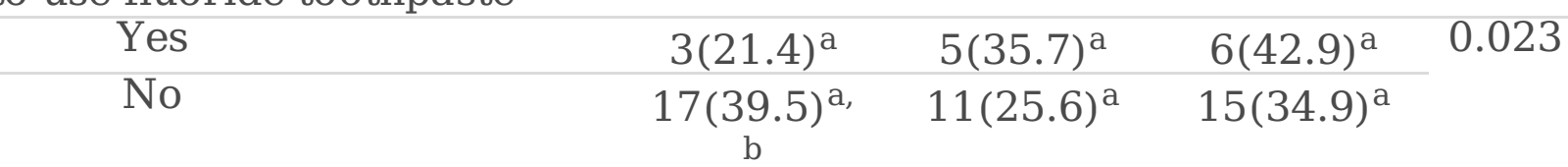

do not know

$71(56.8)^{\mathrm{b}} \quad 32(25.6)^{\mathrm{a}} \quad 22(17.6)^{\mathrm{a}}$

Q12 Has your child had a toothache or discomfort in the past 12 months?

Never

Sometimes

Often

Not clear $179(54.4)^{\mathrm{a}} \quad 88(26.7)^{\mathrm{a}}$

$11(18.0)^{b}$

$0(0)^{a, b}$

$13(61.9)^{\mathrm{a}}$ $21(34.4)^{\mathrm{a}} \quad 29(47.5)^{\mathrm{b}}$

$1(25.0)^{\mathrm{a}}$

$3(14.3)^{\mathrm{a}}$ $3(75.0)^{b}$

$5(23.8)^{\mathrm{a}, \mathrm{b}}$

Q13 Did your child go to the hospital to see the teeth?

$\begin{array}{ccccc}\text { Yes } & 24(35.8)^{\mathrm{a}} & 17(25.4)^{\mathrm{a}} & 26(38.8)^{\mathrm{a}} & 0.006 \\ \text { Never } & 179(51.4)^{\mathrm{b}} & 96(27.6)^{\mathrm{a}} & 73(21.0)^{\mathrm{b}} & \end{array}$

For 4-year-old group $(\mathrm{n}=441)$

Gender

Practice

$\begin{array}{ccccc}\text { male } & 81(37.5)^{\mathrm{a}} & 64(29.6)^{\mathrm{a}} & 71(32.9)^{\mathrm{a}} & 0.033 \\ \text { female } & 61(27.1)^{\mathrm{b}} & 89(39.6)^{\mathrm{b}} & 75(33.3)^{\mathrm{a}} & \end{array}$

Q5 Frequency of eating sweet before going to bed at night

$\begin{array}{ccccc}\text { often } & 10(29.4)^{\mathrm{a}} & 5(14.7)^{\mathrm{a}} & 19(55.9)^{\mathrm{a}} & 0.004 \\ \text { occasionally } & 78(30.2)^{\mathrm{a}} & 89(34.5)^{\mathrm{a}} & \begin{array}{c}91(35.3)^{\mathrm{a}} \\ \mathrm{b}\end{array} & \end{array}$

never

Q8 Brushing times per day

\begin{tabular}{|c|c|c|c|}
\hline 2 times and above & $12(25.5)^{\mathrm{a}}$ & $12(25.5)^{\mathrm{a}}$ & $23(48.9)^{\mathrm{a}}$ \\
\hline 1 time & $44(30.3)^{a}$ & $52(35.9)^{a}$ & $\begin{array}{c}49(33.8)^{\mathrm{a}} \\
\mathrm{b}\end{array}$ \\
\hline not daily brush & $22(44.9)^{\mathrm{a}}$ & $18(36.7)^{\mathrm{a}}$ & $9(18.4)^{b}$ \\
\hline
\end{tabular}

$130(38.2)^{\mathrm{a}} 129(37.9)^{\mathrm{a}}$ 


$\begin{array}{cccc} & 10(13.5)^{\mathrm{b}} & 17(23.0)^{\mathrm{a}} & 47(63.5)^{\mathrm{b}} \\ \text { Often } & 0(0)^{\mathrm{b}} & 3(23.1)^{\mathrm{a}} & 10(76.9)^{\mathrm{b}} \\ \text { Not clear } & 2(14.3)^{\mathrm{a}, \mathrm{b}} & 4(28.6)^{\mathrm{a}} & 8(57.1)^{\mathrm{b}}\end{array}$

Q13 Did your child go to the hospital to see the teeth?

$\begin{array}{ccccc}\text { Yes } & 14(18.4)^{\mathrm{a}} & 15(19.7)^{\mathrm{a}} & 47(61.8)^{\mathrm{a}} & 0.000 \\ \text { Never } & 128(35.1)^{\mathrm{b}} & 138(37.8)^{\mathrm{b}} & 99(27.1)^{\mathrm{b}} & \end{array}$

\section{For 5-year-old group $(\mathrm{n}=445)$}

Knowledge

Q22d Can bacteria cause dental caries?

\begin{tabular}{|c|c|c|c|}
\hline correct answer & $79(25.0)^{a}$ & $91(\underset{b}{28.8})^{\mathrm{a},}$ & $146(46.2)^{\mathrm{a}}$ \\
\hline wrong answer & $9(60.0)^{\mathrm{b}}$ & $1(6.7)^{\mathrm{b}}$ & $5(33.3)^{\mathrm{a}}$ \\
\hline don not know & $28(24.6)^{a}$ & $36(31.6)^{a}$ & $50(43.9)^{\mathrm{a}}$ \\
\hline
\end{tabular}

\section{Attitude}

Q21c_group Is the quality of your teeth related to your own protection?

\begin{tabular}{|c|c|c|c|}
\hline correct answer & $88(24.2)^{\mathrm{a}}$ & $100(27.5)^{\mathrm{a}}$ & $175(48.2)^{\mathrm{a}}$ \\
\hline wrong answer & $28(34.1)^{\mathrm{a}}$ & $28(34.1)^{\mathrm{a}}$ & $26(31.7)^{b}$ \\
\hline
\end{tabular}

\section{Practice}

Q4a Frequency of eating sweet food

\begin{tabular}{|c|c|c|c|}
\hline rare/never & $37(35.6)^{\mathrm{a}}$ & $32(30.8)^{\mathrm{a}}$ & \multirow{2}{*}{$\begin{array}{c}35(33.7)^{\mathrm{a}} \\
30(42.9)^{\mathrm{a}} \\
\mathrm{b}\end{array}$} \\
\hline 1-3 times/month & $20(28.6)^{a}$ & $20(28.6)^{a}$ & \\
\hline 1 time/week & $17(28.3)^{\mathrm{a}}$ & $22(36.7)^{\mathrm{a}}$ & $21(35.0)^{\mathrm{a}}$ \\
\hline 2-6 times/week & $25(22.5)^{\mathrm{a}}$ & $31(27.9)^{\mathrm{a}}$ & $\begin{array}{c}55(49.5)^{\mathrm{a}} \\
\mathrm{b}\end{array}$ \\
\hline 1 time/day & $11(18.6)^{a}$ & $16(27.1)^{a}$ & $\begin{array}{c}32(54.2)^{\mathrm{a}} \\
\mathrm{b}\end{array}$ \\
\hline$\geq 2$ times/day & $6(14.6)^{\mathrm{a}}$ & $7(17.1)^{\mathrm{a}}$ & $28(68.3)^{b}$ \\
\hline
\end{tabular}

Q5 Frequency of eating sweet before going to bed at night

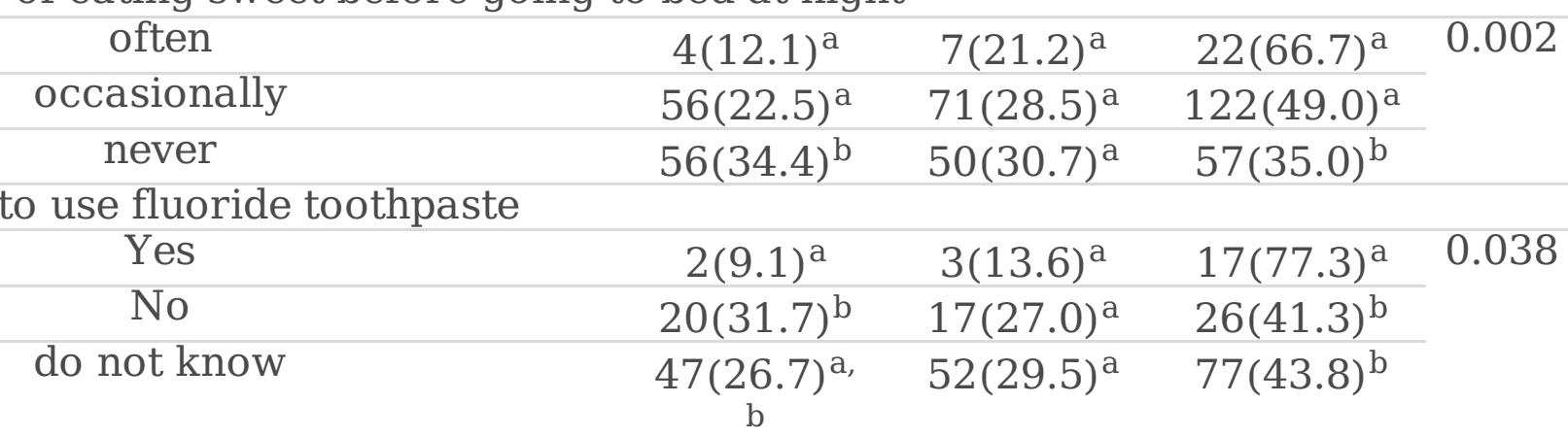

Q12 Has your child had a toothache or discomfort in the past 12 months?

$\begin{array}{cccc}\text { Never } & 102(35.3)^{\mathrm{a}} & 93(32.2)^{\mathrm{a}} & 94(32.5)^{\mathrm{a}} \\ \text { Sometimes } & 10(7.9)^{\mathrm{b}} & 29(23.0)^{\mathrm{a}} & \begin{array}{c}87(69.0)^{\mathrm{b},} \\ \mathrm{c}^{\mathrm{b}}\end{array} \\ \text { Often } & 0(0)^{\mathrm{b}} & 1(6.7)^{\mathrm{a}} & 14(93.3)^{\mathrm{c}} \\ \text { Not clear } & 4(26.7)^{\mathrm{a}, \mathrm{b}} & 5(33.3)^{\mathrm{a}} & 6(40.0)^{\mathrm{a}, \mathrm{b}}\end{array}$

Q13 Did your child go to the hospital to see the teeth?

$\begin{array}{lllll}\text { Yes } & 9(8.7)^{\mathrm{a}} & 25(24.0)^{\mathrm{a}} & 70(67.3)^{\mathrm{a}} & 0.000\end{array}$


a, b, c: Differences in caries rate between row variables in subgroups with different levels of caries, the same mark represents no difference between the two variables.

Table 3. Differential KAP variables in different levels of caries. (n, (\%)) 


\section{\begin{tabular}{lllll}
\hline Groups and variables & $\mathrm{dmft}=0$ & $1 \leqq \mathrm{dmft} \leqq 3$ & $\mathrm{dmft} \geqq 4$ & $P$ \\
\hline
\end{tabular}}

\section{For mild caries group ( $1 \leqq \mathrm{dmft} \leqq 3, \mathrm{n}=394)$}

\section{Knowledge}

Q22e_group Does eating sugar cause dental caries?

Attitude

correct answer

wrong answer or do not know

$$
\begin{array}{cc}
371(52.3)^{\mathrm{a}} & 339(47.7)^{\mathrm{a}} \\
90(62.1)^{\mathrm{b}} & 55(37.9)^{\mathrm{b}}
\end{array}
$$

Q21c_group Is the quality of your teeth related to your own protection?

$\begin{array}{ccccc}\text { correct answer } & 357(52.0)^{\mathrm{a}} & 329(48.0)^{\mathrm{a}} & - & 0.027 \\ \text { wrong answer } & 104(61.5)^{\mathrm{b}} & 65(38.5)^{\mathrm{b}} & - & \end{array}$

\section{Practice}

Q3_group Feeding method within 6 months of birth

complete or mainly breastfeeding complete or primary artificial feeding half breastfeeding and half artificial

\begin{tabular}{|c|c|c|}
\hline $344(51.7)^{\mathrm{a}}$ & $322(48.3)^{\mathrm{a}}$ & - \\
\hline $66(67.3)^{b}$ & $32(32.7)^{b}$ & - \\
\hline $\begin{array}{c}51(56.0)^{\mathrm{a}} \\
\mathrm{b}\end{array}$ & $\begin{array}{c}40(44.0)^{\mathrm{a}} \\
\mathrm{b}\end{array}$ & - \\
\hline
\end{tabular}
feeding

Q12 Has your child had a toothache or discomfort in the past 12 months?

$\begin{array}{ccc}\text { Never } & 411(57.0)^{\mathrm{a}} & 310(43.0)^{\mathrm{a}} \\ \text { Sometimes } & 31(31.6)^{\mathrm{b}} & 67(68.4)^{\mathrm{b}} \\ \text { Often } & 0(0)^{\mathrm{a}, \mathrm{b}} & 5(100.0)^{\mathrm{a}} \\ & \mathrm{b} \\ \text { Not clear } & 19(61.3)^{\mathrm{a}} & 12(38.7)^{\mathrm{a}}\end{array}$

\section{For severe caries group ( $\mathrm{dmft} \geqq 4, \mathrm{n}=446)$}

age

\section{Knowledge}

$\begin{array}{llll}3 & 203(67.2)^{\mathrm{a}} & - & 99(32.8)^{\mathrm{a}} \\ 4 & 142(49.3)^{\mathrm{b}} & -000 & 146(50.7)^{\mathrm{b}} \\ 5 & 116(36.6)^{\mathrm{c}} & - & 201(63.4)^{\mathrm{c}}\end{array}$

Q22d Can bacteria cause dental caries?

\begin{tabular}{cccc} 
correct answer & $328(50.3)^{\mathrm{a}}$ & - & $324(49.7)^{\mathrm{a}}$ \\
wrong answer & $28(70.0)^{\mathrm{b}}$ & - & $12(30.0)^{\mathrm{b}}$ \\
\cline { 2 - 3 } don not know & $105(48.8)^{\mathrm{a}}$ & - & $110(51.2)^{\mathrm{a}}$
\end{tabular}

Q22e_group Does eating sugar cause dental caries?

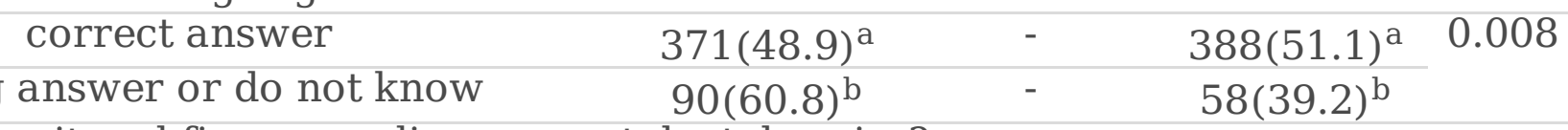

wrong answer or do not know $\quad 90(60.8)^{\mathrm{b}}$
Q22g Can the pit and fissure sealing prevent dental caries?

$\begin{array}{cccc}\text { correct answer } & 60(40.3)^{\mathrm{a}} & - & 89(59.7)^{\mathrm{a}} \\ \text { wrong answer } & 29(60.4)^{\mathrm{b}} & - & 19(39.6)^{\mathrm{b}} \\ \text { don not know } & 372(52.4)^{\mathrm{b}} & - & 338(47.6)^{\mathrm{b}}\end{array}$

Attitude

\begin{tabular}{|c|c|c|}
\hline correct answer & $421(49.8)^{a}$ & - \\
\hline wrong answer & $40(64.5)^{b}$ & - \\
\hline
\end{tabular}

Q21b_group Is regular oral examination necessary?

\begin{tabular}{|c|c|c|c|}
\hline correct answer & $357(48.8)^{\mathrm{a}}$ & - & $375(51.2)^{\mathrm{a}}$ \\
\hline wrong answer & $104(59.4)^{b}$ & - & $71(40.6)^{b}$ \\
\hline
\end{tabular}

Q21c_group Is the quality of your teeth related to your own protection? 


\section{Practice}

$\begin{array}{clll}1 \text { group }(6-7 \text { scores }) & 229(47.7)^{\mathrm{a}} & - & 251(52.3)^{\mathrm{a}} \\ 2 \text { group }(8-54 \text { scores }) & 232(54.3)^{\mathrm{b}} & - & 195(45.7)^{\mathrm{b}}\end{array}$

Q3 Feeding method within 6 months of birth

$\begin{array}{cccc}\text { complete breastfeeding } & 256(49.3)^{\mathrm{a}} & - & 263(50.7)^{\mathrm{a}} \\ \text { mainly breastfeeding } & 88(49.7)^{\mathrm{a}} & - & 89(50.3)^{\mathrm{a}} \\ \text { complete artificial feeding } & 44(74.6)^{\mathrm{b}} & - & 15(25.4)^{\mathrm{b}} \\ \text { mainly artificial feeding } & 22(48.9)^{\mathrm{a}} & - & 23(51.1)^{\mathrm{a},} \\ & \mathrm{b} & & \mathrm{b}^{\mathrm{a}}\end{array}$

half breastfeeding and half artificial feeding
$51(47.7)^{\mathrm{a}}$
$56(52.3)^{\mathrm{a}}$

Q5 Frequency of eating sweet before going to bed at night

\begin{tabular}{cccc} 
often & $27(35.5)^{\mathrm{a}}$ & - & $49(64.5)^{\mathrm{a}}$ \\
occasionally & $252(47.1)^{\mathrm{a}}$ & - & $283(52.9)^{\mathrm{a}}$ \\
\cline { 2 - 4 } never & $182(61.5)^{\mathrm{b}}$ & - & $114(38.5)^{\mathrm{b}}$
\end{tabular}

Q7 Age at which to start brushing

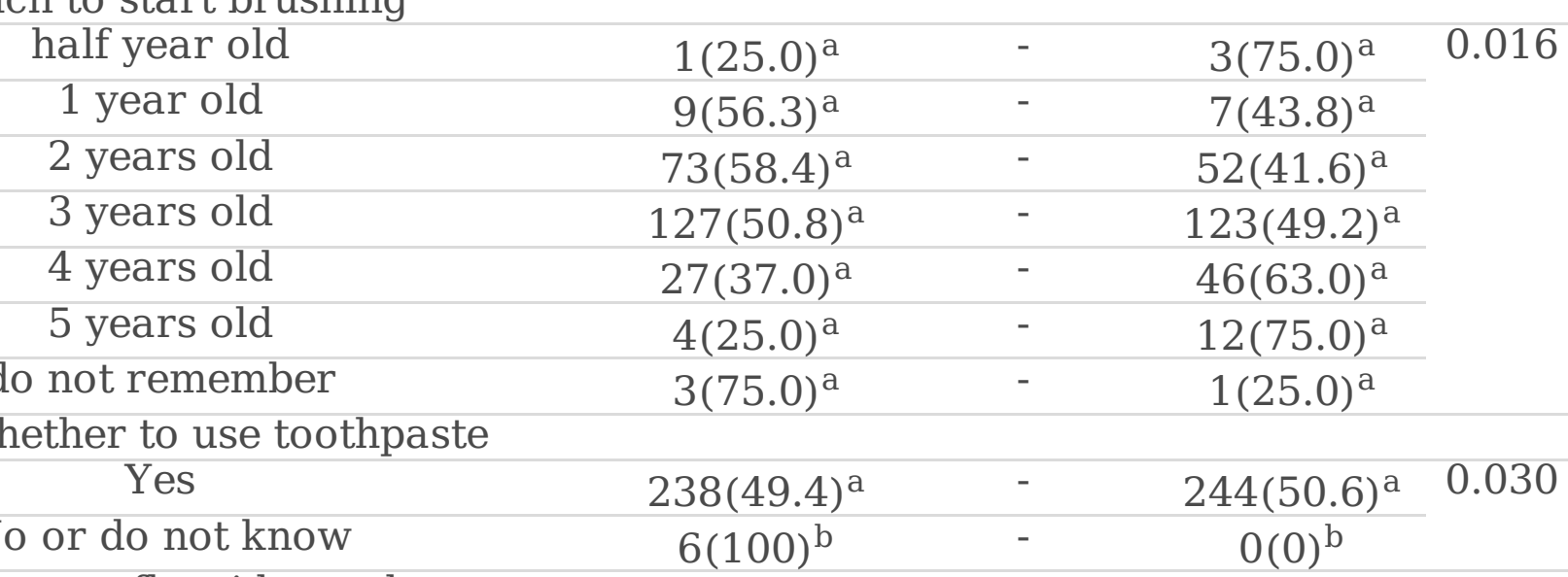

Q11 Whether to use fluoride toothpaste

\begin{tabular}{|c|c|c|c|}
\hline Yes & $12(28.6)^{a}$ & - & $30(71.4)^{\mathrm{a}}$ \\
\hline No & $\begin{array}{c}52(44.4)^{\mathrm{a}} \\
\mathrm{b}\end{array}$ & - & $\underset{\mathrm{b}}{65(55.6)^{\mathrm{a}}}$ \\
\hline
\end{tabular}

do not know $174(53.9)^{\mathrm{b}} \quad-1^{-} \quad 149(46.1)^{\mathrm{b}}$

Q12 Has your child had a toothache or discomfort in the past 12 months?

$\begin{array}{cccc}\text { Never } & 411(63.4)^{\mathrm{a}} & - & 237(36.6)^{\mathrm{a}} \\ \text { Sometimes } & 31(16.0)^{\mathrm{b}} & - & 163(84.0)^{\mathrm{b}} \\ \text { Often } & 0(0)^{\mathrm{b}} & - & 27(100.0)^{\mathrm{b}} \\ \text { Not clear } & 19(50.0)^{\mathrm{a}} & - & 19(50.0)^{\mathrm{a}}\end{array}$

Q13 Did your child go to the hospital to see the teeth?

\begin{tabular}{ccccc} 
Yes & $47(24.7)^{\mathrm{a}}$ & - & $143(75.3)^{\mathrm{a}}$ & 0.000 \\
Never & $414(57.7)^{\mathrm{b}}$ & - & $303(42.3)^{\mathrm{b}}$ & \\
\hline
\end{tabular}

a , b: Differences in caries rate between row variables in subgroups with different levels of caries, the same mark represents no difference between the two variables. 
Table 4. Multivariable logistic regression model for overall. (Ordinal logistic regression analysis)

\begin{tabular}{|c|c|c|c|c|c|c|c|}
\hline all kids & sub-mo & el I) & & only kids with $]$ & $\begin{array}{l}\text { ushing } \\
\text { del II) }\end{array}$ & habits & (sub- \\
\hline Variables & $P$ & OR & 95\% CI & Variables & $P$ & OR & $\begin{array}{c}95 \% \\
\mathrm{CI}\end{array}$ \\
\hline age 3 years old & 0.000 & 0.35 & $0.27-0.45$ & $\begin{array}{l}\text { Age } \\
3 \text { years old }\end{array}$ & 0.000 & 0.34 & $0.24-$ \\
\hline 4 years old & 0.001 & 0.65 & $0.51-0.83$ & 4 years old & 0.009 & 0.65 & $\begin{array}{l}0.47- \\
0.90\end{array}$ \\
\hline 5 years old & NA & 1.00 & NA & 5 years old & NA & 1.00 & NA \\
\hline $\begin{array}{l}\text { 22e_group Does eating } \\
\text { caries? }\end{array}$ & sugar & ause $d$ & ntal & 21_sum_group & & & \\
\hline Yes & 0.022 & 1.39 & $1.05-1.85$ & $\begin{array}{l}1 \text { group(6-7 } \\
\text { scores) }\end{array}$ & 0.021 & 1.40 & $\begin{array}{l}1.05- \\
1.85\end{array}$ \\
\hline No or do not know & NA & 1.00 & NA & $\begin{array}{l}2 \text { group (8-54 } \\
\text { scores) }\end{array}$ & NA & 1.00 & NA \\
\hline $\begin{array}{l}22 \text { g_group Can the pit } \\
\text { prevent dental caries? }\end{array}$ & and fiss & Ire sea & & $\begin{array}{l}\text { 11_group Whet } \\
\text { toothpaste }\end{array}$ & r to us & fluor & de \\
\hline Yes & 0.014 & 1.42 & $1.08-1.88$ & Yes & 0.009 & 1.98 & $\begin{array}{l}1.19- \\
3.31\end{array}$ \\
\hline No or do not know & NA & 1.00 & NA & $\begin{array}{l}\text { No or do not } \\
\text { know }\end{array}$ & NA & 1.00 & NA \\
\hline $\begin{array}{l}\text { Q5 Frequency of eati } \\
\text { bed at night }\end{array}$ & & & & & & & \\
\hline $\begin{array}{c}\text { often } \\
\text { occasionally }\end{array}$ & $\begin{array}{l}0.000 \\
0.000\end{array}$ & $\begin{array}{l}2.55 \\
1.58\end{array}$ & $\begin{array}{l}1.70-3.83 \\
1.27-1.97\end{array}$ & & & & \\
\hline never & NA & 1.00 & NA & & & & \\
\hline
\end{tabular}

OR: odd rates; CI: confidence interval; NA: not applicable.

Table 5. Multivariable logistic regression model for different age groups. (Ordinal logistic regression analysis) 
model 2-1 (For 3-year-old group)

all kids (sub-model I)

only kids with brushing habits (sub-model II)

\begin{tabular}{|c|c|c|c|c|c|c|c|}
\hline Variables & $P$ & OR & $95 \%$ CI & Variables & $P$ & OR & $95 \% \mathrm{CI}$ \\
\hline \multicolumn{4}{|c|}{$\begin{array}{l}21 \mathrm{f} \text { group Does the mother's unhealthy } \\
\text { teeth affect the child's teeth? }\end{array}$} & \multicolumn{4}{|c|}{$\begin{array}{l}\text { 21f group Does the mother's unhealthy } \\
\text { teeth affect the child's teeth? }\end{array}$} \\
\hline Yes & 0.001 & 0.47 & $\begin{array}{l}0.31- \\
0.73\end{array}$ & Yes & 0.002 & 0.35 & $\begin{array}{c}0.18- \\
0.69\end{array}$ \\
\hline No or do not know & NA & 1.00 & NA & $\begin{array}{l}\text { No or do not } \\
\text { know }\end{array}$ & NA & 1.00 & NA \\
\hline 21_sum_group & & & & 21_sum_group & & & \\
\hline $\begin{array}{l}1 \text { group }(6-7 \\
\text { scores })\end{array}$ & 0.010 & 1.71 & $\begin{array}{l}1.14- \\
2.58\end{array}$ & $\begin{array}{l}1 \text { group (6-7 } \\
\text { scores) }\end{array}$ & 0.000 & 3.53 & $\begin{array}{l}1.84- \\
6.76\end{array}$ \\
\hline $\begin{array}{l}2 \underset{\text { scoup }}{\operatorname{gres}}(8) \\
\text { scor }\end{array}$ & NA & 1.00 & NA & $\begin{array}{l}2 \underset{\text { group }}{\operatorname{gcores}}) \\
\text { s-54 }\end{array}$ & NA & 1.00 & NA \\
\hline \multicolumn{4}{|c|}{$\begin{array}{l}\text { 22e_group Does eating sugar cause dental } \\
\text { caries? }\end{array}$} & \multicolumn{4}{|c|}{$\begin{array}{l}\text { Q11 group Whether to use fluoride } \\
\text { toothpaste }\end{array}$} \\
\hline Yes & 0.022 & 1.84 & $\begin{array}{l}1.09- \\
3.11\end{array}$ & Yes & 0.085 & 2.58 & $\begin{array}{l}0.88- \\
7.56\end{array}$ \\
\hline No or do not know & NA & 1.00 & NA & $\begin{array}{l}\text { No or do not } \\
\text { know }\end{array}$ & NA & 1.00 & NA \\
\hline \multicolumn{8}{|c|}{$\begin{array}{l}\text { Q13 Did your child go to the hospital to see } \\
\text { the teeth? }\end{array}$} \\
\hline Yes & 0.003 & 2.13 & $\begin{array}{l}1.30- \\
3.49\end{array}$ & & & & \\
\hline Never & NA & 1.00 & NA & & & & \\
\hline
\end{tabular}

model 2-2 (For 4-year-old group)

all kids (sub-model I)

only kids with brushing habits (sub-model II)

\begin{tabular}{|c|c|c|c|c|c|c|c|}
\hline \multirow{2}{*}{\multicolumn{4}{|c|}{ Variables $\quad P \quad$ OR $95 \%$ CI }} & Variables & $P$ & OR & 95\% CI \\
\hline & & & & \multicolumn{4}{|c|}{ Q8 Brushing times per day } \\
\hline often & 0.006 & 2.66 & $\begin{array}{l}1.32- \\
5.38\end{array}$ & 2 times and above & 0.004 & 3.09 & $\begin{array}{l}1.44- \\
6.60\end{array}$ \\
\hline occasionally & 0.044 & 1.47 & $\begin{array}{l}1.01- \\
2.13\end{array}$ & 1 time & 0.033 & 1.94 & $\begin{array}{l}1.06- \\
3.57\end{array}$ \\
\hline \multirow[t]{4}{*}{ never } & NA & 1.00 & NA & not daily brush & NA & 1.00 & NA \\
\hline & & & & \multicolumn{4}{|c|}{$\begin{array}{l}\text { Q13 Did your child go to the hospital to } \\
\text { see the teeth? }\end{array}$} \\
\hline & & & & Yes & 0.005 & 2.38 & $1.29-$ \\
\hline & & & & Never & NA & 1.00 & NA \\
\hline
\end{tabular}

model 2-3 (For 5-year-old group) all kids (sub-model I)

only kids with brushing habits (sub-model II)

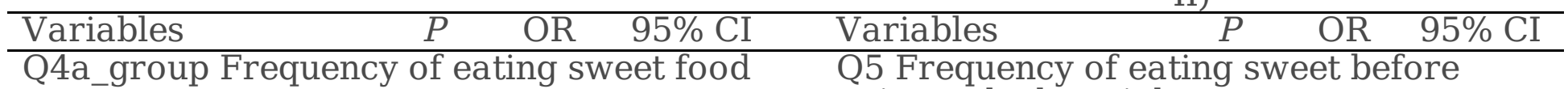

$\begin{array}{lccc}\leq 1 \text { time/week } & 0.001 & 0.55 & 0.38- \\ & & & 0.79\end{array}$

Q5 Frequency of eating sweet before going to bed at night going to bed at night
often
$0.018 \quad 3.88$
$1.26-$

11.89

occasionally

$0.010 \quad 1.89$

$1.16-$

3.08

never NA 1.00 NA

Q11_group Whether to use fluoride toothpaste 


$\begin{array}{cccccccc}\text { often } & 0.020 & 2.59 & \begin{array}{c}1.16- \\ 5.76\end{array} & \text { Yes } & 0.006 & 4.32 & 1.53- \\ \text { occasionally } & 0.009 & 1.66 & 1.13- & \text { No or do not } & \text { NA } & 1.00 & \text { NA } \\ \text { never } & \text { NA } & 1.00 & \text { NA } & \text { NA } & & & \end{array}$

Q13 Did your child go to the hospital to see Q13 Did your child go to the hospital to the teeth?

\begin{tabular}{cccccccc} 
Yes & 0.000 & 3.62 & $2.28-$ & Yes & 0.000 & 2.95 & $1.71-$ \\
& & & 5.77 & & & & 5.08 \\
Never & NA & 1.00 & NA & Never & NA & 1.00 & NA \\
\hline
\end{tabular}

OR: odd rates; CI: confidence interval; NA: not applicable.

Table 6. Multivariable logistic regression model for different levels of caries. (Binary logistic regression analysis)

model 3-1 (For children with 1-3 dmft (MCG))

all kids (sub-model I)

\begin{tabular}{lccclccc}
\hline Variables & $P$ & OR & $95 \%$ CI & Variables & $P$ & OR & $95 \%$ CI \\
\hline age & 0.000 & 1.46 & $1.23-1.73$ & none & & \\
21c_group & 0.014 & 0.64 & $0.45-0.91$ & & & \\
Q3 & 0.035 & 0.89 & $0.80-0.99$ & & & \\
Q12 & 0.025 & 1.28 & $1.03-1.59$ & & & \\
\hline
\end{tabular}

model 3-2 (For children with 4 and more dmft (SCG))

all kids (sub-model I) only kids with brushing habits (sub-model II)

\begin{tabular}{lccclccc}
\hline Variables & $P$ & OR & $95 \%$ CI & Variables & $P$ & OR & $95 \%$ CI \\
\hline age & 0.000 & 1.90 & $1.59-2.27$ & age & 0.000 & 1.92 & $1.49-2.48$ \\
Q5 & 0.000 & 0.58 & $0.45-0.75$ & 21b_group & 0.021 & 0.36 & $0.15-0.86$ \\
Q12 & 0.000 & 2.03 & $1.62-2.55$ & Q5 & 0.035 & 0.69 & $0.49-0.98$ \\
Q13 & 0.000 & 0.30 & $0.21-0.45$ & Q11 & 0.028 & 0.70 & $0.51-0.96$ \\
\hline & & & & Q12 & 0.000 & 2.48 & $1.76-3.51$ \\
\hline & & & & Q13 & 0.000 & 0.41 & $0.25-0.66$ \\
\hline
\end{tabular}

OR: odd rates; CI: confidence interval; NA: not applicable.

\section{Supplementary Files}

This is a list of supplementary files associated with this preprint. Click to download.

- AppendixTableS1.docx 